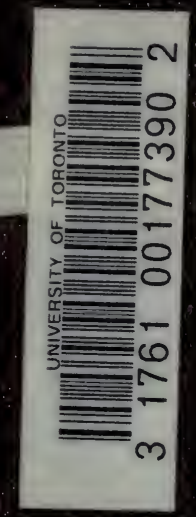




Digitized by the Internet Archive in 2007 


\section{THE FOUNDATIONS OF SCIENCE}

\section{By WILLIAM CECIL DAMPIER (WHETHAM,) M.A., "'F.R.S.}

FELLOW AND TUTOR OF TRINITY OOLLFGE, OAMBRIDGE
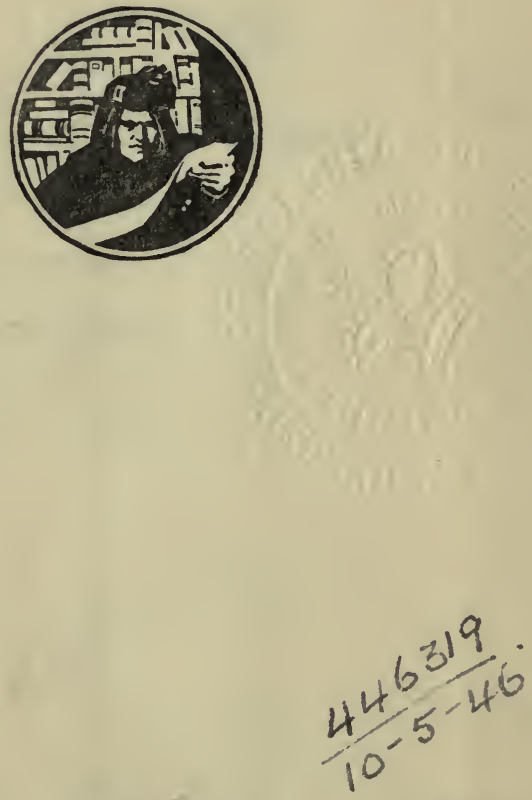

L O N D O N : T. C. \& E. C. J A C K 67 LONG ACRE, W.C., AND EDINBURGH NEW YORK: DODGE PUBLISHING CO. 
Q 159

036 


\section{CONTENTS}

CHAP.

I. THE CLASSIFICATION OF KNOWLEDGE

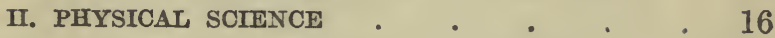

III. BIOLOGICAL SCIENCE • - . - . 51

IV. PSYCHOLOGICAL SCIENCE • . . . 71 



\section{THE \\ FOUNDATIONS OF SCIENCE}

\section{CHAPTER I}

THE CLASSIFICATION OF KNOWLEDGE

THe Latin word scientia, from scire, to learn or know, signifies, broadly, learning or knowledge. But, in general usage, the modern term science has come to mean an ordered knowledge of the phenomena or appearances of Nature, and of the connection or relations which have been discovered between them.

Custom and convenience have divided science into three main sections: physical science, biological science, and psychological science. Although the Greek word $\phi v \sigma \iota s$ (phusis) is perhaps equivalent to the Latin word natura, the name physical is confined, by general agreement, to that part of science which deals with matter and energy. without reference to life. Biological science, on the other hand, treats of living things, and of those special problems of matter and energy to which their life gives rise. Psychological science is concerned 
with the phenomena of mind and the influences affecting it-primarily, of course, with the mind of man, but not exclusively so, since comparative psychology is investigating also the minds of animals.

The relations between the sciences have been the subject of discussion since philosophy, as the science of the sciences, began. While the term science was taken to include the whole of knowledge, the problem of classification was more complicated, and perhaps more important, than it is if we accept the modern more limited view. The problem of the classification of knowledge is one of much difficulty; and any scheme, such as that which is now suggested, must not be regarded as final. The branches of knowledge are not only growing within themselves, but their relations to each other are continually changing, so that the scheme of arrangement suitable for one age may not be appropriate for another.

As regards science, the three main divisions we have adopted seem to be related as follows. Physical science, the knowledge of the phenomena of matter and energy, on one side touches biology, the science of living things. Biology, in its turn, touches psychology, the science of mind, since mind, as we can investigate it by scientific methods, is always contained in living organisms, or, at all events, is always investigated in relation to such organisms.

So far all seems simple; and we are inclined to 
represent our model of science as a sequence of subjects, with physical science at one end, biology in the middle, and psychology at the other end-a sequence like that of the colours of the rainbow, where red represents physics, green biology, and blue psychology, physics appearing out of the invisible as a faint, purplish glow, and psychology fading away into a haze of violet, not very different from the purple basis of physics.

\section{Purple Red Yellow Green Blue-Green Blue Violet}

\section{Fig. 1.}

And, indeed, we are led back by psychology to approach logic, physics, and the other sciences we have traced, from a new standpoint. Psychology gives us insight into the theory of knowledge, and leads us critically to examine how it is that we know anything, either by logic or by the senses, or by that fertile union of the two which breeds science. Thus, by the road of psychology, we return once more to our starting-point, ready to study fundamental, logical, mechanical, and physical ideas from a critical point of view.

We shall do well, then, to bend our spectrum round so that the violet theory of knowledge, which lies beyond the blue of psychology, shall be brought near to the purple of logic, where fundamental scientific 


\section{THE FOUNDATIONS OF SCIENCE}

ideas take their rise and pass into the red of definite physics.

We may picture these relations to our eye in a manner, originally suggested by Newton, and now used to illustrate Maxwell's theory of colour vision. On that theory, as we shall see later, there are three primary colour sensations: red, green, and blue. These colours are placed at the corners of a triangle,

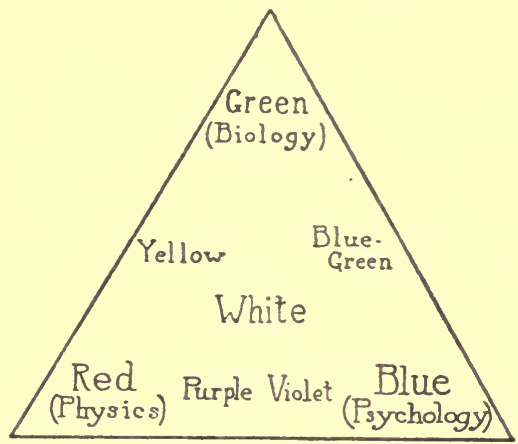

FrG. 2.

and points within the triangle are tinged with complex colours made up of the three primaries in proportion to the nearness of the points to the three corners.

Now, as before, let us take red to represent physical science, green biology, and blue psychology. The points of the triangle represent the purest sciences: red represents physics in the strict sense, green the natural history of plants and animals, and blue pure 
CLASSIFICATION OF KNOWLEDGE 11

psychology. Moreover, a number of complex sciences involve combinations of physics, biology, and psychology in different proportions, and are represented by points within the triangle, where the colours are mixtures of the primaries.

Let us begin a more detailed survey somewhere in the purple region, at the beginnings of physical science. Here we find the so-called laws of thought, logic both verbal and symbolic, the latter containing the fundamental principles of mathematics. A little further on are the developments of pure mathematics leading to, and elsewhere lying side by side with, the methods of applied mathematics ready for use in physical problems. Then comes mechanics, experimental in its principles, but largely formed in detail by mathematical deduction from those principles. The next region of our figure, the red corner, contains, more or less side by side, the various branches of physics proper: heat, light, sound, electricity and magnetism. Here, too, we may place chemistry, which in its essence is probably only a branch of molecular physics, though it may extend further along the length of the side of the triangle, and run more into the biological region than do some other subjects comprised in physics.

Next we pass into the yellow region-the physics and chemistry of vital processes, one aspect of physiology, animal and vegetable. With the other aspect, that concerned first with the cell and then 


\section{THE FOUNDATIONS OF SCIENCE}

with the living organisms as a whole, where green first becomes visible, we come on a new factor, the tremendous factor of life. Comparative physiology introduces us to different types of animals and plants, which are studied from another point of view in the almost pure green of the natural history of the zoologist and field botanist.

In contact with all the biological section devoted to animals, and perhaps just touching that concerned with plants, blue becomes visible in our diagram, and we find once more a new phenomenon, which transcends mere life as life transcends lifeless matter - the phenomenon of mind and consciousness. Here we enter psychology, that study of mind which is of immemorial antiquity on the one side of introspection, and is of the newest group of sciences on the other, as a matter of experimental observation. It touches physiology most closely of the biological sciences, so that physiology, which comes in contact with chemistry and physics, must be pictured in our diagram as a region of space running across the whole of that portion of the triangle given up to biology.

From psychology we pass to the theory of knowledge, and thus we complete the circuit of our figure. We find ourselves once more at our starting-point of logical principles, which, on one side, have affinities with psychology, since they are apprehended by the direct action of our minds, and on the other are the basis of physics and all other sciences. 
The parts of the triangle lying nearer the centre correspond with complex sciences, which need the conceptions of all three primaries. Astronomy lies in the purple region, where the chief elements are mathematics and physics; geology, in the yellow, depends chiefly on physics and biology. Historical and political science, a greenish-blue, is built up chiefly on psychology and biology, but it is affected by the physical structure of man, by the physical conformation of the earth and heavens, and by those mechanical laws in conformity with which mankind always has had to live. Thus physical science is also involved.

As we approach the white central point we come to those great subjects which need a proportionate knowledge of all sciences for their treatment, the subjects of metaphysics, the study of the nature of reality; philosophy, the science of the co-ordination of knowledge; and theology, in its widest sense the study of the meaning and purpose of the universe, both external and internal.

But how are we to picture to ourselves the use of this coloured triangle, this scheme of science, in the examination of the knowable both within and without ourselves?

Let us suppose that we are placed in a room, the only window of which is a triangle of glass coloured in accordance with our diagram. 


\section{THE FOUNDATIONS OF SCIENCE}

We examine objects in the room by light which comes through the window, and we look at the landscape without through the same coloured glass. Before the ages of accurate scientific experiment, no precautions were taken to isolate different coloured lights, or to look steadily for a time through one part of the window. But gradually it was found that the confusion of colour and light which had disturbed man's vision could be obviated. By covering all the window with a movable shutter in which a single small hole was cut, and placing the hole at the point corresponding to any one science, a view both of the room and of the world without was obtained by the light of that one science only-things were seen steadily in one aspect.

Moreover, men slowly invented methods of examination of greater and greater power. These methods we may illustrate in our analogy by the idea of telescopes of gradually increasing magnification, with which we may look through the hole in the shutter at the outside world, and slowly improving lenses and microscopes for the investigation of objects within the room.

"To see life steadily and see it whole," we must use successively light from all available sciences. If we use but one colour we get a mental picture of creation tinted by that light alone. If we use the white light of the central metaphysical region only, we fail to detect the complex nature of that white 
CLASSIFICATION OF KNOWLEDGE 15

light itself, and fail also to discover a host of new relations which are brought out successively as our different coloured lights are employed one after another.

Now, all this is only an allegory. It is not meant that there is any real connection between knowledge and a triangle, or that physicists in reality see things red and psychologists blue. Yet analogies have their uses. They prove nothing; but they may give clarity of vision to a mind which, without them, would be confused; they may even serve to suggest new relations which perhaps, when suggested, can be demonstrated and confirmed by more logical and rigorous methods. Let our allegory be recognised as such, and, however little it may help, it can do no harm. 


\section{CHAPTER II}

\section{PHYSICAL SCIENCE}

THE origin of mechanical science is to be sought in the efforts to understand the tools and instruments invented by man to supply his bodily needs, and the phenomena of motion as seen in Nature.

The lever, the inclined plane, and the wedge are pictured in the carved stone records of Egypt and Assyria, and their practical use was known before the dawn of history. But the first who attempted to obtain a scientific explanation of the principles which underlie their application was the GreekSicilian philosopher, Archimedes of Syracuse, who lived from the year 287 to the year 212 before Christ.

Archimedes was educated at Alexandria, where Euclid had taught fifty years earlier. And he threw his investigations into the form which Euclid had used with so much success in geometry.

He begins by laying down axioms, or what are considered as self-evident propositions, and deduces from them, in the Euclidean manner, the law of the lever-a law that may be stated as follows. If a 
light bar be balanced over an edge, the weight at the end of the shorter arm must be greater than that at the end of the longer arm in the same proportion as the greater length is to the shorter, or the product of the weight and its distance from the point of support is the same on each side.

But, if his proof of this proposition be examined it will be found that he assumes a property, that of the centre of gravity, which is, in reality, equivalent to the principle of the lever. Moreover, some of his axioms can only be justified by experiment. We may, in fact, just as well investigate the law of the lever directly by the experimental method, and use it, when established, as the basis of further deductions.

Nevertheless, Archimedes' attempt to explain the lever in terms of phenomena which he regarded as better known, was an immense step in advance, and is, in truth, the type of all scientific explanations, which can consist only in expressing the less known. in terms of the better known. To the mind of Archimedes and his contemporaries, his axioms appeared better known than his conclusion, and his proof was therefore to them a true explanation.

To us, steeped in the experimental method, it seems better to base the subject on the law of the lever, a law which lends itself readily to experimental verification, than on the principle of the centre of gravity, which, in its general form, cannot be demonstrated so easily by experiment, though it may 


\section{THE FOUNDATIONS OF SCIENCE}

appear more "self-evident" to minds unused to experimental investigation. We see clearly from this first illustration that a physical "explanation" is merely a restatement of our result in terms of others more familiar to the particular minds which are dealing with the problem at the time.

It is to Archimedes, also, that we owe the first clear ideas about the phenomena of floating bodies. Before his work on weights in relation to volumes, the conceptions which we call density and specific gravity were unknown. He showed that when a body floats in a liquid, partially or wholly immersed, its own total weight must be equal to the weight of that part of the liquid which it displaces.

Very little advance in mechanics was made from the time of Archimedes till, nearly two thousand years later, first that universal genius Leonardo da Vinci (1452-1519) and then Simon Stevin of Bruges (1548-1620) again took up the problem of the lever, and dealt also with the inclined plane and the general conditions of equilibrium of three forces acting in a plane. Here again the form of the proof is that of Euclidean geometry, the chief axiom being the instinctive recognition that an endless chain, lying along an inclined plane, hanging down from its top and passing beneath it and so round, will not continue in perpetual motion. This is the real advance, the increased insight into what is or is not experimentally possible. 
Thus Leonardo and Stevin had placed the science of statics, or the knowledge of the laws of forces in equilibrium, on a sound basis. But no corresponding advance had been made in the subject of dynamics, which deals with the phenomena and laws of motion; though here, too, some signs of progress appear in the notebooks of Leonardo. The ideas current were still held on the authority of the Greek philosopher Aristotle, and it was believed that bodies fell to the earth because each body sought its natural place owing to an intrinsic property of heaviness or lightness, the "place" of heavy bodies being below and that of light bodies being above. From these ideas it followed that, the heavier a body, the faster it must fall.

Galileo Galilei (1564-1642), with the instinctive genius of the great man of science, saw that the whole point of view must be changed. Instead of inquiring with Greek philosophers and mediæval schoolmen why things fell, he set himself, in true modern fashion, to examine experimentally how they fell.

For two thousand years men had tamely accepted Aristotle's teaching, that heavy bodies fell faster than light ones, when five minutes' experiment by dropping lumps of stone and iron from a cliff or high building would have sufficed to prove it erroneous. Galileo showed his at first incredulous contemporaries that heavy and light bodies, let fall simultaneously from the top of the Leaning Tower of Pisa, reached 


\section{0}

THE FOUNDATIONS OF SCIENCE

the ground together, so long as the lighter body was not sufficiently light to be retarded seriously by the resistance of the air. Aristotle was shown to be wrong, and a new era had begun.

A falling body moves faster and faster as it travels through space, and Galileo next set himself to examine how this increase of velocity occurs. His first supposition was that the speed was proportional to the distance travelled, but he soon convinced himself that this idea was wrong. Then he tried the hypothesis that the speed increased with the time of fall, and cast about for a means of putting the relations to the test of experiment.

Bodies falling freely moved too fast to be dealt with by the primitive apparatus then available, and, to get a manageable velocity, Galileo assumed that a ball rolling down an inclined plane would follow the same kind of rule as a ball falling freely, though it would fall with less speed.

On the hypothesis that the speed of fall increased with the time, he caiculated the distance which the ball should roll, and showed that it should be proportional to the square of the time; that is, if the ball roll 1 foot in 1 second it will roll 4 feet in 2 seconds and 9 feet in 3 seconds. This result he proceeded to test.

His clocks were not sufficiently accurate or convenient, and so, to measure times, he took a large vessel with a small hole in the bottom which he closed 
with his finger. The vessel was filled with water, and the finger removed and replaced at the beginning and the end of the time-interval to be measured. The water flowing out was collected and weighed.

In this way, Galileo verified by experiment the result of his assumption, and, in this case, no other hypothesis would lead to the same result. Hence the hypothesis that the speed is proportional to the time of fall is confirmed in one instance. Further experiments gave similar results, and general belief in the hypothesis as true was established.

It remained to deal with the actual speed of a body falling freely. This Galileo examined as follows. He showed that a body sliding down one plane would run up another of the same total height whatever be the length of the slope of the planes. Hence it followed that it was the height alone that mattered, and that a body falling freely would acquire the same velocity as a body sliding down an inclined plane, provided that the total height descended were the same in each case.

But an even more important result followed from the investigation with the two planes. A body sliding down one plane acquired velocity enough to carry it up the other to an equal vertical height. However long were the second plane, and however gently inclined, if friction were negligible, the same result was obtained. It was the vertical rise alone that destroyed the velocity. Hence it followed that, in 
the extreme case, where the second plane was supposed to be made horizontal, no destruction of velocity would occur, and, friction apart, the body would move straight forward for ever with uniform velocity.

To appreciate the revolution in science which this conclusion produced, it is necessary to describe shortly the beliefs it displaced. In ordinary life, we are accustomed to see moving bodies brought to rest by impact with the earth, or by friction, or by other opposing agency ; and this experience led to the idea that motion always required the continuous exertion of some force to maintain it unimpaired. Hence followed in astronomy the invention of vortices to uphold the planetary motions, and in terrestrial dynamics similar confusing conceptions had been introduced.

At one blow Galileo destroyed all such theories, and cleared the ground for new building.

But before we deal with those who, in this work, entered into his labours, it is worth pausing to consider the improvement in method as well as the actual advance in knowledge effected by Galileo. To study Galileo's researches after those of his predecessors is like coming out into the light after groping about in a dark room. In mechanical science, he is the first of the moderns, and his methods are a model of physical investigation for all time. $\mathrm{He}$ uses experiment in its right place, and scientific 
imagination also, to frame hypotheses to guide his experiments, and to bo checked, verified, or disproved by his experiments.

Contemporary with Galileo, Lord Chancellor Bacon (1561-1626) was philosophising in England over scientific method. In a healthy reaction from the errors of scholasticism, Bacon laid exclusive stress on experiment. But he went too far, in teaching that by experimenting in all directions, scientific laws will appear without noed of deductive reasoning. Galileo, who did not philosophise, but had the true scientific instinct for what was practicable and helpful, went straight to the right method.

In the question of the fall of heavy and light bodies, he saw at once that a crucial experiment was possible. He dropped two bodies from the Leaning Tower, and the question was settled. Here wo have the simplest kind of investigation. One thing is believed on the word of authority. No one has thought of testing it. Galileo, seeing reason to doubt, is not content with the opinion of Aristotle as to what ought to occur. He goes and tries what does occur.

In his work on the law of velocity of fall, we have a more complicated problem. It was untouched before; any result was possible. If he had worked by the Baconian method, Galileo would have made endless experiments on falling bodies, till relations forced themselves on his notice. He did nothing of the kind. As a beginning, he sat and thought. He 


\section{THE FOUNDATIONS OF SCIENCE}

then made a guess at a possible law :-that the speed of fall was proportional to the distance fallen through. He reasoned out the consequences of this hypothesis, and found that they were self-contradictory. His guess was clearly wrong.

He tried again. He tried the supposition that the final speed varied as the time of fall. Here the consequences deduced were consistent; the hypothesis was worth testing by experiment.

But the hypothesis itself was not fitted for direct experiment-at all events, by means of Galileo's apparatus. Therefore he took one of its consequences, which he had obtained by deductive mathematical reasoning - the consequence that the distance fallen should be proportional to the square of the time.

He had now formulated his experimental problem, and had to face the practical mechanical difficulties. First, he improved the conditions of the process from the experimental point of view, reducing the velocity by making the falling body run down an inclined plane instead of fall freely through space. Secondly, having no apparatus delicate enough to measure the small intervals of time involved, he invented a new form of water-clock for this special purpose. Thus, the conditions being made favourable, and his apparatus being made adequate, he measured the times taken by the falling body to run over marked distances on the inclined plane. Small divergences 
in individual experiments appeared: but, on the average, his results showed that the distances traversed from rest were proportional to the squares of the times of fall.

He had now verified one of the consequences of his hypothesis. In this case it was enough, because, if that consequence be assumed, the original hypothesis may be shown to follow necessarily. Thus the original hypothesis was verified also, and it was certain that, as he supposed, the velocity of fall of his ball increased with the time. Repetition of the experiments has but served to confirm this result, and gradually, by this process of induction, complete conviction has been forced on us that it is a general law of nature that the speed of falling bodies increases in proportion to the time of fall.

In one respect all physicists are not so lucky as Galileo. It cannot always be shown that the original hypothesis is the only one consistent with the deduction from it which is chosen for submission to an experimental test. If not, all verifiable consequences of the original hypothesis must be deduced, and as many of them as possible examined experimentally. With each concordance the evidence in favour of the original hypothesis is increased, till eventually a very high degree of probability may be obtained.

Galileo's method, extended to cover this further case, is that by which advance has been made in physical science from his day to ours. 
And now, let us return to Galileo's great discovery that, left to itself, a body moves on in a straight line with uniform velocity. The need for vortices to maintain the motion of the planets was thus done away, and it became clear that what cried for explanation was not the continued motion, but the continual deviation from the straight course involved in circular or elliptical orbits. Some force must be acting, drawing the planets towards the centre.

Isaac Newton (1642-1727), a young graduate of Trinity College, Cambridge, had returned for a time to his home in Lincolnshire, driven out of Cambridge by the Great Plague of 1665 . In this retirement he set himself to apply Galileo's dynamical principles to known astronomical events. At that time the Ptolemaic system of astronomy, which made the earth the centre of all things, had recently been given up by all competent philosophers in favour of Copernicus' (1473-1543) revival of the theory that the sun is the centre of our system. Tycho Brahe (15461601) had collected an immense number of observations on the motions of the planets, and, by a lifelong study of his data, John Kepler (1571-1630) had formulated laws which described the motions: laws such as the statement that the planets describe ellipses with the sun in one focus.

Taking the simplest case, the revolution of the moon in a nearly circular orbit round the earth, it occurred to Newton that, as the moon moves in a 
circle instead of in Galileo's straight course, perhaps the familiar force of gravity, by which an apple falls to the ground, might be the cause also of the moon's continual fall towards the earth.

It was probable that any force directed towards a central point, and operative throughout surrounding space, would vary inversely as the square of the distance. And, on this hypothesis, Newton calculated what the effect of gravity would be at the distance of the moon. Misled at first by an inaccurate value of this distance, he found that the actual fall of the moon towards the earth was less than that calculated. But, six years later, a redetermination of the size of the earth gave a different value for the moon's distance, and enabled Newton to show that gravity, which is operative on the earth's surface, is the effective cause of the moon's circular motion.

Newton's next great achievement was the geometrical proof that the inverse square law would explain the motion of the planets in ellipses, and that no other law would do so. Then, on the assumption that each particle of matter produced its own effect, he showed that a sphere attracted as though all its mass were concentrated at a central point, and was hence led to the final form of his theory, that every particle of matter in the universe attracts every other particle with a force that varies inversely as the square of the distance between them.

For two years Newton was absorbed in the task 


\section{THE FOUNDATIONS OF SCIENCE}

of working out the consequences of this theory, by mathematical methods often invented by him in the process. At the end of that time he had placed the theory of the heavens on a mechanical basis, and the publication of Newton's Principia in 1687 marks the greatest step ever made in the advance of knowledge.

Besides the creation of gravitational astronomy, Newton placed the science of mechanics firm on the base prepared by Galileo. He first formulated clearly the distinction between the mass of a body, invariable and unalterable in all conditions of mechanical experiment, and its weight, which depends on the attraction of the earth, and would vanish altogether at some point between the earth and the moon where their pulls were equal as well as opposite. He collected the principles of mechanics, which had now become clear as the result of inductive reasoning from experience, and expressed them in three laws. These laws, the summit of the inductive process, collect and state in short-hand form the experimental knowledge of mechanical phenomena. In turn, the laws are the starting-point of the deductive science of mechanics, in which, by mathematical reasoning, ideal cases of motion may be investigated. These ideal cases may be suggested by actual physical phenomena to which they may be made to approach more or less nearly. The nearer be the concordance between an actual case we wish to investigate and the ideal and usually simplified 
case we can examine mathematically, the closer is the actual result found to conform with that predicted by calculation. Our imaginary mathematical model seems to represent the observed mechanical phenomena of Nature in a very accurate manner, until, at all events, we have to take into account velocities approaching that of light.

Let us now examine this picture or model of Nature which mechanical science presents to our eyes.

In watching any motion we are conscious of two main perceptions: those of space and time. The moving body describes a certain length of path and takes a certain time to do so-a time which our mind measures in terms of its sequence of consciousness. Length and Time, then, are taken as fundamental concepts of the mind, corresponding to the direct sense-perceptions of space and time.

From these fundamental concepts, others follow, The Velocity of the moving body is measured by the length moved over in a given time, or, writing the result in the initial letters as symbols,

$$
v=\frac{L}{T}
$$

Again, if the velocity vary from instant to instant, its change in unit time gives its rate of change, that is, the acceleration of the moving body. Hence

$$
a=\overline{\mathrm{T}}=\frac{\mathrm{L}}{\mathrm{T}^{2}}
$$




\section{THE FOUNDATIONS OF SCIENCE}

and we have expressed acceleration in terms of our fundamental concepts of length and time.

In order to co-ordinate these purely conceptional relations with experimental quantities and to apply them to practical measurement, we need units. The units of length arose originally from the average dimensions of the human body, the yard from a convenient arm-span, the foot from the length of a man's foot. But, as the need of accuracy increased, mechanical models of the units in general use were constructed, and the legal yard became the length between two marks on a standard bar, and the foot the third part of that length. The French units, framed by the confident science of the revolutionary period, took the dimensions of the earth as a standard. But the legal metre is no longer the ten-millionth part of one earth quadrant, but the length between marks on a standard bar, which a re-measurement of the earth has shown appreciably to differ from the supposed relation.

The ides of time depends on human consciousness, but as this differs from man to man, and even in one man at different stages of his life, the periodicity of astronomical phenomena was early taken as a better practical standard. The day or the year may be taken as our fundamental unit, and the second, or practical scientific unit, defined as a fraction of either of them. With the units of length and time, and the derived units of velocity and acceleration, any system 
of motion may be described. In these terms we may specify the configuration of any system of moving bodies at any instant and specify its changes. But for a complete science of mechanics another concept is needed.

Our sense of sight may give us an idea of motion, but, if an external body comes in contact with us, owing to relative motion, our sense of touch gives us a new perception, that of force, and our muscular sense gives us a rough measure of its intensity.

It would be possible to construct a scheme of mechanics with force as a third fundamental unit, but, as a matter of convenience, another procedure is better. The concept of mass, which, in terms of consciousness, may be taken as derived from that of force, is a better basis for practical mechanics, because it may be imagined to keep constant for any one body throughout a series of changes.

If we support two bodies so that their weights are not operative-place two large stones, say, on smooth ice-we shall find that if, being of identical substance, they differ in size, to set them in equal motion requires either different forces or equal forces exerted for different times. The same result holds with two fly-wheels of the same size, one of iron and one of wood. The iron wheel needs more force to set it in motion, and more force to stop it when once set going.

We express these facts by saying that the mass of 


\section{THE FOUNDATIONS OF SCIENCE}

the large stone is greater than that of the small stone, and the mass of the iron wheel greater than that of the wooden one, in the proportion of the forces needed to give them the same accelerations. Hence the idea of the mass of a body is reached by considering the force required to give it a certain acceleration.

It will be seen that in these relations the idea of weight is not involved, and there is no reason to predict that the weight of a body bears any simple relation to its mass as defined above. It is a matter of experiment to investigate the connection, if any, between them. But the necessary experiment had already been made by Galileo, before Newton placed the concept of mass on a sound footing. Since bodies, whether heavy or light, fall to the ground at the same rate, their accelerations are the same. Hence it follows that the forces acting, that is, the weights of the bodies, are proportional to their masses which those forces have to move.

The mass of a body, then, is proportional to its weight, and the masses of bodies are compared, accurately and easily, by the familiar process of weighing them.

The unit of mass is defined, like that of length, in terms of a standard. England has a standard pound and France a standard kilogramme, with which other pounds and kilogrammes can be compared and must conform.

When we have added the unit of mass, $\mathbf{M}$, to those 


\section{PHYSICAL SCIENCE}

of length and time, we have the complete Newtonian framework of mechanical science. From these three units all other mechanical units may be derived.

For instance, force, as we have seen, is a direct sense-perception, and therefore might be made a fundamental physical concept; but it is treated in practical science as a unit derived from the unit of mass, which, though theoretically derived, is more convenient to take as fundamental. The mass of a body is defined by the force required to produce a given acceleration, and so force is measured by the product of the acceleration and the mass of the body on which it acts, or $\mathrm{F}=\mathrm{M} a$.

Again, work or energy is defined as the product of a force into the distance the force moves its point of application, so that, in terms of fundamental units, energy is $\mathrm{FL}=\mathrm{MaL}$, or since $a$ is $\mathrm{L} / \mathrm{T}^{2}$ we get

$$
\text { Energy }=\frac{M L^{2}}{T^{2}}
$$

Newton's formulation of dynamics has held undisputed sway till, in recent years, it has been shown that the effective mass of an electrically charged body in motion increases as the velocity of light is approached. But, whatever be the outcome of recent discussion, at all velocities possible in mechanical experiment, Newtonian results are in accordance with practical observation. 


\section{THE FOUNDATIONS OF SCIENCE}

Although the concept of mass was only formulated clearly by Newton, the problem of matter, the most characteristic property of which is mass, is at least as old as the Greek philosophers. The influence of this age-long familiarity is evident in Newton's handling of the subject; for, instead of defining mass in terms of force, he defined it as "the quantity of matter in a body," and treaied force as a derived unit. But, in truth, matter is best known to us through its mass, though historically matter itself seems the more familiar idea.

Even among the Greeks two views of the nature of matter were held. One theory taught that it was continuous and infinitely divisible into similar parts, so that water was water however far the subdivision went. But Leucippus and Democritus put forward the opposite view that, at a certain stage, division could go no further, and that there ultimate particles or atoms would be reached. On this atomic theory, the different properties of various substances were due to differences in the size, structure, and arrangement of particles of the same ultimate nature.

But this speculation was in advance of the age, and no facts or experiments could then be adduced in its verification. Hence, when it was criticised by Aristotle in the light of his own preconceptions, it withered away. It was revived by the Roman poet Lucretius, but Aristotle's influence alone sur- 
vived the Dark Ages, and dominated later mediæval thought.

Galileo's experiments banished from mechanics the conception of a body intrinsically light; but, misled by the phenomena of flame, chemists still represented burning as the loss of a substance, phlogiston, which, since the balance showed a simultaneous gain, must possess the Aristotelian property of a negative weight. It was not till, towards the end of the eighteenth century, the discovery and investigation of several new gases had changed the point of view, that burning was recognised as a combination with oxygen, one of the gases of air, and phlogiston vanished from the nomenclature of science.

Chemical change was then seen to be concerned with bodies all essentially of the same nature, and a detailed study of chemical combinations showed that a compound always contained the same definite proportions of its elements; while, if two elements formed more than one compound, simple relations held between the proportions in the different compounds in which the elements combine.

In 1808 John Dalton (1766-1844) saw that these relations were best explained by a revival of the old atomic theory, the combining weights of the elements giving a clue to the relative weights of their respective atoms. By the further investigation of the laws of the combination of gases, the conception of the 


\section{6}

chemical atom, as the smallest reacting particle, was made more definite, and distinguished from the conception of the physical molecule, the smallest particle which could exist in the free state. In this form, the theory is based on definite experimental evidence, and not on speculative philosophical views about the nature of matter, as it was in the days of the Greeks.

Chemistry is the direct descendant of mediæval alchemy, which sought to transmute base metals into gold, and to prepare an elixir vitoe or essence of life, but in its search discovered many less harmful things. By the investigation of the properties of gases, and by the introduction of Dalton's atomic theory, chemistry was placed firm on its modern footing, where its conceptions have influenced all other branches of science, and have become the basis of the immense superstructure of molecular physics.

One of the earliest developments of molecular physics was due to J. P. Joule (1818-1889), who from 1840 to 1850 revolutionised the theory of the nature of heat. Boyle (1627-1691), Newton, and other acute thinkers, had previously held the view that heat was due to the agitation of the ultimate particles of bodies; but, in the absence of the modern conception of energy, such a theory gave no foundation for the measurement of heat as a quantity constant throughout a series of changes. Hence, as often appears in the history of science, a theory which was 
more nearly in accordance with the knowledge of a later age was useless, and useful advance was made in the light of a theory which after times rejected. When Black (1728-1799) discovered the phenomena of specific and latent heat-the different amounts of heat needed to warm different substances, and the heat required to melt solids and evaporate liquids-he found a better working hypothesis in the rival theory of heat as an imponderable, invisible fluid. This conception suggested at once the idea of heat as a constant measurable quantity, and on it the science of calorimetry, or the measurement of heat, was founded.

However, observations accumulated rapidly which pointed to another view of heat, and linked it with a wider range of phenomena. Count Rumford (17531814) by the boring of cannon, and Sir Humphry Davy (1778-1829) by the friction of two pieces of ice in a vacuum, showed that an unlimited amount of heat could be obtained-an amount roughly, at all events, proportional to the work expended.

But the fluid theory still persisted, and it was not till Joule measured carefully the heat developed in friction by known amounts of work that it was generally relinquished. Joule found that the same amount of work, whether mechanical or electrical, and however expended, always developed exactly the same amount of heat-that, in effect, heat and work were equivalent and interchangeable. This result gave definiteness and point to a vague fore- 


\section{THE FOUNDATIONS OF SCIENCE}

shadowing of the theory of energy known as the correlation of forces. Energy now emerged as an exact conception-the power of doing work, to be measured by the amount of work done. Moreover, in Joule's experiments, if heat be taken as a form of energy, the total energy is constant in amount, what was lost in work being gained in heat. In this case, then, we have definite experimental proof of the conservation of energy. Although no such exact proof can be given in all cases, the cumulative evidence is very strong that in all physical and chemical changes we may imagine a quantity which is unchanged in amount throughout the changes, a quantity which may be transformed by friction into an equivalent amount of heat, and may be identified with energy as defined above.

While mass is constant at all moderate velocities, and energy is conserved in all conditions known to us, other quantities are conserved only in limited conditions. Thus in pure Newtonian mechanics we find a conservation of momentum; and, in those special changes which in thermodynamics are called reversible, we recognise the constancy of another quantity which is termed entropy. But neither momentum nor entropy are conserved in physical and chemical changes generally; and we are hence led to a cautious attitude in similar cases. While energy is constant in all conditions known to science, we must not be too sure that science has studied 
all possible conditions in all possible depths of the universe.

Mechanical and electrical work may be transformed completely into heat by means of friction or resistance; but the reverse operation can only be completed in very special circumstances. The conditions of the limited change which is usually alone possible are of great importance in the theory of heat engines, and are the subject of that branch of science known as thermodynamics. All heat engines must possess a hot body or source of heat and a cold body or condenser, and the transformation of heat into work will be more complete, and the engine therefore more efficient, the greater the difference of temperature between the source and the condenser. The change can only be complete if the temperature ratio be infinity-that is, if the temperature of the condenser be zero. Hence is reached the conception of a true absolute zero of temperature, unconnected with the properties of any particular thermometric substance like mercury, a zero which has been approached more and more nearly as one gas after the other has been liquefied.

Simultaneously with this development in the science of heat, a great advance was made in the kindred subject of light. Newton was the first to give a satisfactory demonstration of the really complex nature of white light, and to resolve it completely 


\section{THE FOUNDATIONS OF SCIENCE}

into its coloured constituents by means of a prism.

Newton felt the necessity of imagining space to be filled with a subtle medium or æther, though the difficulty of accounting by any then known theory of waves for the transfer of light in straight lines or rays led him to suppose in addition that light consisted of streams of minute particles or corpuscles shot off from the luminous body with immense velocity.

The pure wave theory, however, had already been developed by Huygens (1629-1695), but it was not till a century later that Young (1773-1829) and Fresnel (1788-1827) succeeded in establishing it in general estimation. In their hands the new theory explained satisfactorily all the phenomena then known, especially those of the interference of two rays of light to produce coloured fringes. When two waves come together, if their crests coincide their joint effect will be the sum of their individual effects; but, if the crests of one wave coincide with the troughs of the other, their effects will be opposite and may destroy each other. Hence some constituents of a dual beam of white light may be destroyed, and colour appear as the result of the remainder

Similarly, when the wave-length is very small compared with the dimensions of the obstacles or the distances concerned, the fact that light travels in straight lines is explained by the interference of all parts of the possible wave-front except a small area which forms an advancing ray. 
Thus the chief difficulty in the wave theory of light was overcome, while the phenomena of polarisation, seen when light is passed through such bodies as crystals of Iceland spar, showed that the direction of vibration of the waves must be at right angles to the direction of propagation of the light. This observation indicated some of the properties with which the hypothetical æther of space must be endowed if it be to serve as the medium through which these waves can travel.

The wave theory led directly to the explanation of the black lines crossing the coloured band of light or spectrum which is obtained by passing sunlight through a glass prism. A theory of these lines had been given by Sir George Stokes (1819-1903), but it was not till the theory was reintroduced by the German chemists Bunsen (1811-1898) and Kirchhoff (1824-1887), and verified by experiment, that it was generally accepted. A child's swing is set in motion by giving it a series of gentle impulses in time with its own natural period, and any mechanical system will absorb energy which falls on it in similar periodic unison with its own vibrations. The molecules of the vapours in the outer envelope of the sun will absorb the energy of particular rays coming from the hotter interior when the waves coincide in oscillatory period with the molecules. The light which passes on will be deprived of those particular constituents-that is, of those particular coloured rays-and black lines 


\section{THE FOUNDATIONS OF SCIENCE}

corresponding to this omission will cross the solar spectrum.

These conditions were reproduced in the laboratory by Bunsen and Kirchhoff, who passed the intense white light of an electric arc through sodium vapour volatilised in the cooler flame of a spirit lamp, and obtained the black absorption line of sodium in the resulting spectrum.

By this discovery the whole new field of the constitution of the sun and stars was opened to chemistry, which found proof of the existence of its familiar terrestrial elements in the depths of space. Moreover, spectrum analysis soon detected new elements both on the earth, where rare alkalies came to light, and in the sun, where an unknown spectral line suggested a new element, helium, only afterwards detected on the earth in the gases hidden in certain minerals.

But these methods of research have done more than reveal the chemical nature of celestial bodies. If the source of light and the observer are approaching each other, more waves per second reach the eye than if they were relatively at rest. Hence the colour of a simple ray and its position in the spectrum are slightly changed. By measuring microscopically such displacement of known lines in the spectra of stars, their relative velocity of approach or recession in the line of sight may be estimated-a feat which might well have been thought impossible of attainment. 
The most far-reaching development in physical science during the nineteenth century was in the domain of electricity. When the century opened, the Italian Volta (1745-1827) had only just discovered the pile or cell which enabled experimenters to obtain a steady electric current instead of the isolated charges alone available before.

It was soon found that these electric currents produced magnetic forces, and, by the invention of galvanometers, instruments in which these forces were used to deflect magnetised needles, the currents were brought within the power of measurement, and the electric telegraph made possible. The complementary discovery of Faraday (1791-1867), that the movement of a magnet would produce an electric current, barely perceptible to his apparatus, gave rise to the astonishing development of electro-magnetic machinery of the second half of the century.

Faraday's researches were largely inspired by his repugnance to the idea of action at a distance, and his consequent continual search into the properties of the insulating medium through which electric forces must exert themselves. Clerk-Maxwell (18311879) interpreted and extended Faraday's ideas in mathematical form, and showed that the properties of the medium, which were necessary to explain the electrical effects, were identical with those already required to explain the propagation of light.

Hence it became possible to conceive of light as 


\section{THE FOUNDATIONS OF SCIENCE}

a series of electro-magnetic waves, and this theory was immensely strengthened by Hertz (1859-1894), who, twenty years after Maxwell, succeeded in producing long-wave electro-magnetic disturbances by purely electrical means, and in demonstrating their existence and properties. Improvements in the details of the apparatus soon made possible the use of wireless telegraphy.

The chemical effects of electrical currents were the first of their properties to be examined, and in after years led to the most striking of the triumphs of modern physics in the results of the study of the conduction of electricity through gases.

When an electric current is passed between metallic terminals or electrodes through the solution of a salt, the salt is decomposed chemically. The products of the decomposition appear at the electrodes only; the body of the solution is unaltered. To explain these facts, it is necessary to suppose that a movement in opposite directions of the opposite parts of the salt is going on. From the conductivity of the solution it is possible to calculate the relative velocity with which these moving parts, or ions-travellers -make their way through the liquid. The calculated velocities have been confirmed experimentally by watching the motion of coloured ions.

A relation discovered by Arrhenius, a Swedish physicist, between the conductivities and the chemical activities of solutions, made it plain that, in some 
cases at all events, the ions which were effective electrically were also the agents in chemical activity. This discovery gave precision to the connection long suspected between electric forces and chemical affinity, and led to a great development in the theory of physical chemistry, which, during late years, has been largely inspired by the ideas of the ionic hypothesis.

The conception of electric ions, originally due to the investigation of the electrical properties of solutions, has been used with striking success in the explanation of the kindred phenomena of the conduction of electricity through gases.

When the air or other gas in a glass vessel with metallic electrodes is gradually pumped out, an electric spark passed between the electrodes becomes a broadened band of luminosity, separated from the negative electrode or cathode by a narrow, dark space. As the exhaustion of the gas proceeds, this dark space grows till it fills the vessel, the walls of which then show green phosphorescent effects, and become the source of the remarkable rays discovered by Röntgen and now used with great success in surgery.

At this stage the phosphorescence may be shown to be due to the bombardment of the glass by streams of minute particles, shot off from the cathode and known as cathode rays. These particles may be deflected by magnetic and also by electric forces, and must therefore be charged electrically, the 


\section{THE FOUNDATIONS OF SCIENCE}

direction of the deflection indicating a negative charge. There is good reason to believe that the charge is equal to that on the liquid ion, and hence, from the measured values of the deflections, Sir J. J. Thomson was able to calculate the mass of the particles, as well as their velocities.

In this way Thomson made the remarkable discovery that, whatever be the residual gas or the material of the electrodes, the mass of these cathode particles was the same, and equal to about the eighthundredth part of the mass of the lightest atom known to chemistry-that of hydrogen. In these ultra-atomic "corpuscles" the old conception of a basis common to all types of matter has been realised at length.

The corresponding positively electrified rays, on the other hand, proceeding from the positive electrode, are never of less than atomic dimensions, but consist of streams of electrified atoms or molecules derived mainly from the gas left in the vessel. From the magnetic and electric deflections, the atomic weight of these positive carriers may be measured, and thus the particles identified among the atoms and molecules of chemical substances.

The phosphorescence produced by the impact of Röntgen rays on certain substances suggested that these substances themselves might emit radiations. In a search for such effects, Becquerel discovered that salts of uranium emitted spontaneously rays 
with a superficial resemblance to Röntgen rays, but that there was no connection between this effect and the phenomena of phosphorescence.

M. and Mme. Curie soon observed that certain ores of uranium were more active than their contents of uranium warranted, and, searching for the cause, they gradually separated an intensely active salt, to the metallic base of which they gave the name radium.

Radio-active substances, of which radium is the most striking example yet discovered, emit at least three kinds of radiation, now distinguished by the Greek letters $\alpha, \beta, \gamma$. The $\alpha$ radiation is easily absorbed by screens. It may, though with difficulty, be deflected from its straight path by magnetic and electric forces, and is thereby shown to consist of positively electrified particles having the mass of helium atoms. The $\beta$ radiation is much more penetrative. It is easily deflected, and shown to be identical in nature with the cathode ray stream. It is made up of negatively electrified projectiles like Thomson's corpuscles, though the $\beta$ rays possess higher velocities, sometimes approaching that of light to within some five per cent. The $\gamma$ rays seem to resemble Röntgen rays.

Radio-activity is always accompanied by chemical change, and the rate of change indicates that it is of the nature of a dissociation of particles acting singly. The amounts of energy liberated are very much greater than any connected with ordinary chemical actions, and the whole of the evidence suggested to Rutherford 


\section{THE FOUNDATIONS OF SCIENCE}

and Soddy the theory now accepted, that radioactivity consists in the explosive disintegration of isolated chemical atoms, atomic and sub-atomic projectiles being shot off, till a simple atomic residue is left behind.

All the types of radiation possess the power of making a gas through which they pass a conductor of electricity. The rays, as they impinge on the molecules in their path, produce gaseous ions. It is by this effect that they are chiefly investigated. Our methods for the detection of electric effects are so sensitive that Rutherford and C. T. R. Wilson have been able to trace the effects of single $\alpha$ particles as one by one they are shot off by disintegrating radio-active atoms. In this marvellous way, by watching the motions of the needle of an electrometer, or the formation of lines of cloud in the air in a glass vessel, has the effect of the atomic structure of matter been made visible to the human eye.

If, from one point of view, the cathode ray corpuscles and the $\beta$ particles of radio-active changes can be regarded as sub-atomic particles of matter, from another they are ultimate units of negative electricity. An atom with one corpuscle too much is an atom negatively electrified, while a defect of a corpuscle from the normal number means positive electrification.

But here we come in contact with another line of 
inquiry. If light be an electro-magnetic wave, it must originate in the vibrations of electric charges, and from this idea a theory of matter was built up by Lorentz and Larmor. The ultimate particle became electrical in nature, and matter was resolved into a collection of disembodied electric unit charges or electrons. When Thomson's corpuscles became known, they were identified with the electrons of Lorentz and Larmor.

A moving electric charge is accompanied by electromagnetic energy and momentum in the surrounding medium, and thus work must be done to set the charge in movement or to stop it when travelling. Here we have an explanation of the familiar phenomenon of mass or inertia-we explain, in fact, Galileo's law of continued motion in terms of an electrical theory of matter.

In this way the conception of matter has been resolved into that of electricity, and a striking unity reached between the two branches of science, dynamic and electrical.

But, as we have no special electrical sense, mechanical force is a more familiar conception to our minds than electrical force. Hence, perhaps, arise the efforts which have been made to express an electric charge in its turn in mechanical conceptions, such as a strain knot in the luminiferous æther.

Whatever be the fate of these attempts, there seems no philosophical reason, save the structure of 
our bodies and minds, for preferring a mechanical explanation rather than an electrical one. To explain everything in terms of æther is but to shift the mystery of the physical universe on to the conception of a medium itself hypothetical.

Nevertheless, such a unification of physics, could it be attained, would fulfil the highest aim of pure science. Metaphysics is concerned with the ultimate nature of reality, but the more modest aim of science is the construction of a consistent model of phenomena and their relations-a model which shall be logically consistent when examined by our minds, and consistent, according to its own convention, with the observed appearances of Nature. Any simplification in that model is a step in advance, and a unity such as that of which glimpses are now vouchsafed to us would satisfy our legitimate desires for scientific knowledge.

But it is not certain that unity will be obtained by the conception of a luminiferous æther, which for half a century has dominated physical science. It is possible that the field of electro-magnetic energy surrounding an electric charge in motion moves with it, and that the vibrations of light travel through this moving field, instead of through an ocean of stagnant æther. These ideas, and the so-called Principle of Relativity arising out of them, may be the direction in which unity is next to be sought. 


\section{CHAPTER III}

\section{BIOLOGICAL SCIENCE}

As the origins of physical science are found in the observation of natural mechanical phenomena and the use of primitive tools, so the beginnings of biology are to be sought in the observation of wild animals and plants, the gradual domestication of some of them, and the rise of a rational medicine and surgery from the chaos of ideas which preceded it.

The cultivation of plants, such as the cereals, most of which seem to have been originally natives of the lands round the Eastern Mediterranean, had not been conducted entirely at haphazard. The writers of classical times, who wrote on agricultural subjects, laid great emphasis on the necessity of saving seed from the largest and finest plants for next year's crop; showing that the effects of selection had been noticed, and the idea of a progressive improvement in natural qualities had been put in execution, some two thousand years before the inward meaning of such a conception affected the growth of knowledge as a whole.

In the purely observational sciences of natural 
history considerable progress was made by the Greeks. Aristotle, for instance, gave an extended account of the animals known in his day, with some details of their anatomical structure. But in medicine, where preconceived theories about the nature of man or the origin of disease could be used as a basis of deductive reasoning, the Greeks' love for this type of philosophy led them astray. But even here, in the school of Hippocrates (450 B.c.), rational ideas began to emerge.

The first systematic study of human anatomy appears to have arisen in Alexandria under the sway of the Ptolemies, induced, perhaps, by the Egyptian custom of embalming the bodies of the dead. From Alexandria, too, a knowledge of Greek learning spread among the Moors and Arabs, by them to be reimported into Western Europe when the chaos of the dark ages which followed the decay and fall of Rome was giving place to better days.

The great revival of thought and learning which took place in Europe throughout the thirteenth century proved singularly unfertile in the advance of scientific knowledge. Francis, Lord Bacon, writing three hundred years later, comments on the unserviceable character of the facts gleaned by the men of learning up to that period, and calls attention to the want of direction and organised system which impeded mankind in the advance towards mastery over the forces of nature. 
When the full stream of the recovery of the ancient writings reached Europe in the years of the Renaissance, it was thought that science would show the same marvellous development that literature and philosophy had undergone. Hence at first medicine sought to solve all its problems by the wisdom of the ancients rather than to build up a sound system by the painfully slow methods of observation and experiment. Isolated revolts were led, especially by Leonardo da Vinci and Paracelsus (1490-1541), against the tyranny of Greek authority, but it was not till 1543, when Vesalius taught anatomy from his own observations, that the true method was generally used. In 1628 William Harvey applied the methods of the new anatomy to the problems of physiology, and, as a first-fruits, revealed the mechanism of the circulation of the blood.

From that point growth was rapid, helped by the new physical knowledge, by the application of the microscope, by experiments on living animals, and by the development of a less fantastic scheme of chemical knowledge than that which had been current among the earlier alchemists.

The growth of medicine and the demand for new drugs reacted both on chemistry and botany. In the former science it led to the discovery of many substances before unknown, while in the latter, besides inducing the cultivation of useful herbs, it caused more intimate research into the structure and 


\section{THE FOUNDATIONS OF SCIENCE}

uses of plant organs. The sexual functions of the ovaries and anthers were made clear by Camerarius in 1694, while the following century saw a complete system of classification worked out by Linnæus (1707-1778).

Interest and curiosity about the animal world had always been more marked than about plants, which only attracted attention in so far as they were useful or harmful in medicine or agriculture. From the stories of Pliny and the anecdotes of beasts current in the ancient world, some of which at least were based on misconceptions or existed only in the imagination, we pass to the Bestiaries, elaborately written and illuminated in the monasteries of the thirteenth and fourteenth centuries. Travellers such as Marco Polo had brought back tales of animals from India, China, and Africa, while the discovery of America opened up a whole continent of unknown animal and plant life. These stories were soon followed by the capture and production of the animals themselves, and natural history, from being too often a collection of incredible marvels, took its place among the recognised branches of systematic knowledge.

In the seventeenth century the study of animals was stimulated by the foundation of Royal Menageries, while improvements in the microscope led first of all to a more detailed study of cell structure, and 


\section{BIOLOGICAL SCIENCE}

afterwards disclosed the existence of multitudes of micro-organisms, hitherto unsuspected.

But with all these studies of existing plants and animals it was long before men fully realised that authentic traces of extinct forms of life were to be found in the fossils embedded in the rocks. Isolated glimpses of this truth are seen here and there in the fifteenth and following centuries, but it was not till the eighteenth century that this view was consistently advocated. Hutton's (1726-1797) Theory of the Earth, published in 1785, taught that processes still going on were adequate to explain the formation of the stratified rocks, and the existence of embedded fossils. But even then no general agreement followed, and it was not till Lyell (1797-1875) collected all the evidence that had accumulated in his Principles of Geology (1830-33) that men of science were convinced, and realised that ages must have elapsed in geological processes, beside which the few thousand years of the received Biblical chronology were almost as nothing.

The long series of fossil animals and plants of gradually increasing complexity, found by geologists in strata of different ages, raised once more the question of the evolution of species. The idea of the development of all existing forms of life from a few simple types had been held by some of the Greek philosophers, but it had vanished in the ascendancy of the Biblical story of the Creation, and been dis- 
credited further by the scientific doctrine of fixity of species prevalent in the eighteenth and early nineteenth centuries.

Lamarck (1744-1829), it is true, had advocated a theory of evolution founded on the idea of the gradual development of organs under the stimulus of special use for many generations-the giraffe, for instance, acquiring its long neck by the continual efforts of its ancestors to browse on trees just beyond their reach. But no evidence was forthcoming of the inheritance of such acquired characters, and the balance of scientific opinion was decidedly against the evolutionary hypothesis.

In 1858, however, a new suggestion was made independently by Charles Darwin (1809-1882) and Alfred Russel Wallace (b. 1823), fortified in the case of Darwin by illustrations drawn from many years' observation and experiment. Impressed by the severity of the struggle for life and for mates among animals and plants in a state of nature, Darwin and Wallace saw that a variation in structure or character which gave even a slight advantage to any individual might determine the question whether or not it was to survive, obtain a mate, and rear offspring. Innate variations tend to be inherited, and thus a favourable variation might be perpetuated, developing in time into a new variety or species. In this way, the pressure of natural selection might accentuate chance variations, and produce 
from a few prototypes all the existing species of living beings, gradually, throughout the long ages of geological time, moulding each species to suit its environment, and leaving it more fixed in type as the need for variation disappeared.

When this theory had overcome the opposition of those who held a too literal interpretation of the book of Genesis, it became the dominating idea of the second half of the nineteenth century. Its influence extended far beyond the confines of biological science. By giving a reasonable explanation of biological development, it justified the conception of evolution in general, and that conception was applied with varying measures of success to co-ordinate the phenomena of cosmical processes, the development of the human race, historical change, and social evolution. Even the specific idea of natural selection, or the survival of the fittest-the fittest for the particular existing environment-found application in other realms of thought. In especial it illuminated the tendencies of sociology, or the science of human societies, where progress has followed along much the same lines previously trodden by natural history. From the mere collection of tales of the marvellous and surprising, such as were at first brought back by travellers, traders, and missionaries-whose calling took them among unknown peoples-the study of mankind has advanced into the careful, sympathetic, and intelligent stage, which is now characteristic of 


\section{THE FOUNDATIONS OF SCIENCE}

anthropology and the allied subject of comparative religion. The results of the patient labour of spade and pick, among the sands of Egypt, and the waste cities of Palestine and Asia Minor, by which the relics of past civilisations have been brought to light, may be compared with the unfolding of the story of evolution by the study of the fossil contents of rocks. But there are yet vast areas awaiting the coming of the scientifically trained and equipped explorer. The remains of the ancient peoples in the central districts of Asia are still unmapped, and the great inscriptions of Central America have so far baffled all attempts to decipher their record. Nevertheless the causes which have contributed to the rise and fall of civilisations are beginning to yield their lessons for the future.

Mankind is subject to evolution, and the average composition and character of each race is always changing, not only absolutely but in relation to other nations. Hence arises the importance of a study of the comparative rates of reproduction of different sections of a nation, and of other agencies that may affect racial qualities-the subject-matter of the study named Eugenics by the late Sir Francis Galton (1822-1911), its founder.

While Darwin was still at work, another series of researches was being carried out on inheritance, which only became generally known many years 
later. G. J. Mendel (1822-1884), Abbot of Brünn, not satisfied with the theory of natural selection of small variations as a sufficient cause of evolution, investigated the effects of crossing different kinds of green peas.

Mendel's discovery consists essentially in the disclosure that in heredity certain characters are transmitted as indivisible units. In peas the tall and dwarf varieties show these phenomena. Tallness and dwarfness here are opposite unit qualities, and the products of a cross between tall and dwarf parents are not intermediate in character. In the first generation all the seedlings are outwardly like their tall parents : hence tallness is said to be "dominant" over the "recessive" dwarfness. But, when selffertilised, these tall hybrids reveal their difference with their dominant parent. Instead of breeding "true," and giving consistently tall offspring, the second generation is found to consist of talls and dwarfs in the ratio of three to one. All the dwarfs breed true in future, but of the talls one-third only breed true, while two-thirds reproduce in the third generation the mixed result of the second.

These relations are explained directly and easily by the supposition that the germ cells of the plants are in character either "tall " or "dwarf," so that a hybrid has some "tall" germ cells and some "dwarf" but no intermediate variety. When a dominant (D) tall plant is crossed with a recessive 


\section{THE FOUNDATIONS OF SCIENCE}

(R) dwarf, its own germ cells are half $\mathrm{D}$ and half R. If self-fertilised, or crossed with a similar plant, on the average of large numbers, it must chance that about half the unions will be between $\mathrm{D}$ 's and R's to form DR's, while half will be pure bred, being divided equally between DD's and RR's.

But since " tallness" is dominant, any plant which contains "tallness" at all in its composition grows tall, and so all the DR's resemble the DD's outwardly, and we get three-quarters of the seedlings apparently tall. But, when crossed among themselves or selffertilised, these DR's reveal their true nature in their offspring.

We may illustrate this scheme in a pedigree diagram-

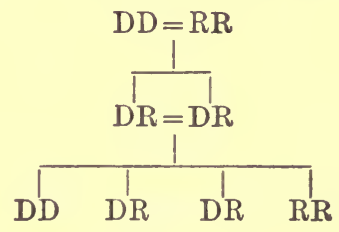

In other cases, more complicated relations appear. Qualities may be linked, so that one cannot appear without the other, or may be antagonistic, and never exist together. Other qualities may only be found in one sex, or be dominant in one sex and recessive in another.

Mendelian characters have been proved to exist in many plants and animals. The insight which this 
knowledge gives into the problems of cross-breeding has already resulted in the raising of new and valuable types of wheat, and bids fair to revolutionise the arts of the stock-breeder and horticulturist. In mankind Mendelian relations have been established for eye colour, where brown pigment in the iris is dominant, and in certain diseases and malformations. In these cases, the probable result of marriages of affected persons can be estimated accurately, and the proportion of their children likely to show the special characteristic has become a matter of exact calculation.

If our growing knowledge of heredity promises greater final results, more practical gain has hitherto been obtained from that branch of biology, which has revealed to us the existence and life history of those micro-organisms which have been proved so powerful for good or ill to mankind.

The Greeks and Romans had noticed and speculated on some of the diseases which we now know are caused by microbic action. The connection between marshy districts and malarial fever seems always to have been recognised. Mildew or rust in wheat had also attracted attention, and the Romans, after the beginning of our era, associated its prevalence with inclement and damp weather, and with ground that lay low and was exposed to heavy dews. The diagnosis so far was correct, as well as the 


\section{THE FOUNDATIONS OF SCIENCE}

further idea that something from the outside had come in and attacked the crop, which was expressed in the view that either the moon, the Milky Way, or some heavenly body had let fall an infecting substance. The remedy proposed, namely that a young dog should be sacrificed, probably to conciliate the constellation of Sirius (the dog-star), is however a part of the classical treatment of the subject which would find no analogue in modern science.

The putrefaction of decaying animal and vegetable matter, also, had been a subject of speculation from the earliest times, and the fermentation produced by yeast has also been known throughout history. Yet it was not till about 1838 that Schwann (1810-1882) discovered that the activity of yeast was due to the growth and multiplication of living cells, and that putrefaction was caused by a similar process.

These results were extended about 1855 by Pasteur (1822-1895), who traced all such changes to the introduction of living cells or germs of cells, and thus destroyed the old idea of spontaneous generation. Pasteur detected the specific microbes of chicken cholera and the silk-worm disease, and gradually our knowledge of microbic diseases has been extended, chiefly by inoculation experiments on living animals, and we have learnt how to guard against some of the worst of these microscopic but deadly enemies. To this knowledge we can trace most of the modern improvements in sanitation and hygiene. 


\section{BIOLOGICAL SCIENCE}

In many cases the action of the microbe on the body it attacks is directly due, not to the microbe itself, but to a chemical substance, or enzyme, it produces. In 1897 this process was first demonstrated by Büchner for the fermentation of yeast : its characteristic effects could be induced by a substance extracted from the cells. These enzymes seem themselves to remain unchanged at the end of the action, their presence alone being sufficient to work the changes.

The history of the discovery of the true nature of malarial fever may be taken as a typical example of the romance of modern biology. The forging of the first link in the chain was due to Laveran, a French army doctor, who, in 1880, detected living parasites in the blood of a malarial patient. The clue was followed up in Italy, where the life history of these microbes was studied. Three distinct groups were distinguished at first, corresponding to three different forms of the disease prevalent at different periods of the year. The interest now centred in finding the means by which the infection was introduced into the body of man; naturally, some suctorial insect was soon suspected. In 1895, Ross and Manson were able to demonstrate the existence of the identical parasites in mosquitoes which had fed on the blood of infected persons, and showed how the parasites increased in size, divided, and became full of threadlike spores until their progeny filled the body cavity 


\section{THE FOUNDATIONS OF SCIENCE}

of their insect host. By means of the bite of an infected insect, the disease was recommunicated to a human host, and a new cycle of existence was entered upon.

Only one particular type of the mosquito or gnat family, to which the name Anopheles has been given, seems to serve in the distribution of malaria fever, and among them the females are the bloodsuckers. Species of this insect are found in almost every part of the world, including England, and it is from the study of their habits of life that malarial fever has been swept away from many of its old haunts. These gnats breed in stagnant water, and seldom fly about except between sunset and sunrise. The breedingplaces can be destroyed by some system of drainage, or by the filling in of places where pools of water are apt to collect. Again, a thin layer of petroleum oil over a sheet of water which cannot be drained, will prevent the development of the larva. Wire gauze screens to windows and doors and mosquitonets round beds will protect the inhabitants during the period of the night, when these creatures are active.

Malarial fever or ague was once well known in the fen districts of England, but it was stamped out, probably by the progressive drainage, and the successful treatment of the occasional sufferer by quinine, before the true cause of the disease had been ascertained The mosquito which conveyed the infection 
still exists, but it is no longer infected by the specific parasite. Thus it seems possible to look forward to the entire elimination at some time of any one particular microbe, and so to remove its characteristic disease from among the human race.

The success which attended the researches on malaria has led to an extension of this branch of preventive medicine in many directions. The ravages of Mediterranean or Maltese fever among the troops and crews of the men-of-war stationed in those regions led to the appointment of a committee of inquiry. A specific organism causing the disease was again discovered; and it was found that it spent one of the necessary stages of its existence in the goats, which form an important part of he economic wealth of the Mediterranean agriculturist. Thence the infection is transferred to men in the milk, butter, or cheese derived from these animals. The goats themselves, however, show no signs of feeling any discomfort from the presence of the parasite. This immunity of the animal host from any obvious form of disease constitutes one of the most baffling features in the pursuit of this class of knowledge.

Whole districts of Central and East Africa are ravaged by epidemics and maladies in man and beast, such as sleeping sickness, blackwater fever, and others, by which some areas have been rendered almost uninhabitable; and various animals, previously unsuspected, have been shown to play their 


\section{THE FOUNDATIONS OF SCIENCE}

part in spreading the infection. Moreover, the various races of mankind manifest different degrees of susceptibility to different forms of infection; and in a few cases persons have been found who, like some animals, are apparently immune to the consequences of infection, but are nevertheless acting as hosts to the parasite, and are spreading the disease amongst those with whom they come in contact.

The application of Pasteur's results to the prevention of microbic infection in the operations of surgery by Lord Lister (1827-1912), in conjunction with the discovery of anæsthetics, made possible the surgical advances which have done so much to relieve human suffering, and have changed our hospitals from institutions in which recovery was at best doubtful into the most effective agencies for the preservation of human life.

The result of the improvements in hygiene, medicine, and surgery is best measured by the drop in the annual death-rate in cities from some eighty per thousand of the population two hundred years ago to the present value of about fifteen per thousand. Not only does this change mean lives prolonged which otherwise would have been sacrificed, but it means also increased health and strength for some who, in old conditions, might have survived with impaired vitality. Nevertheless, we must not forget that this alteration in the incidence of death and disease involves dangers of its own. Mental and 


\section{BIOLOGICAL SCIENCE}

physical defects which in former ages would have destroyed their owner, and with him ceased from troubling the human race, are now sometimes perpetuated in his offspring, whose existence has been made possible by this same improvement in the conditions of life. If the innate qualities of our race are to improve in the future as they have done in the past, if indeed the race is to be preserved from decay, such problems will have to be faced.

We must now consider briefly the relations between physics and chemistry on the one hand and the biological sciences on the other.

The bodies of plants and animals are clearly subject to the usual laws of mechanics. As wholes they fall with the usual acceleration of gravity; their limbs illustrate the mechanical principles of the lever. The breathing of animals is analogous chemically to the burning of a candle, and organic bodies are composed of the same chemical elements that are familiar in the inorganic world.

Nevertheless, carbon, which must be regarded as the chief and most characteristic element in organic matter, possesses properties more complicated than those of other elements. A carbon atom is able to combine with other carbon atoms, as well as with those of different substances, to form very complex molecules, and it is this property which makes possible the special chemistry of living processes. 
Paracelsus (c. 1490-1541) and Stahl (1660-1735) carried into modern times the old ideas of a distinct vital principle, in opposition to the equally old theory that the mechanism at work in the inorganic world was sufficient completely to explain the phenomena of life. Till comparatively recent times, the vitalist thought that the characteristic organic compounds could be produced by life alone, and were beyond the resources of chemical laboratories.

But in 1828 Wohler (1800-1882) succeeded in preparing artificially the typically organic compound urea, and thereby threw doubt on the prevalent vitalistic hypothesis. Other preparations followed, till in 1887 Fischer and Tafel produced sugar from its elements.

Simultaneously many physical processes have been found operative in living tissues. In particular the phenomena of solution have thrown light on many of the physiological problems of living cells; osmotic pressure and the motion of electric ions are the means by which many of the operations of living tissues are carried on.

In this way much new insight has been obtained on the mechanism, both physical and chemical, by means of which the functions of life are maintained. Nevertheless, the gap between the inorganic world and the world of life shows no signs of being bridged. We are still unable to produce the simplest living cell from dead matter. All known organisms are 
derived from parents of like nature. But, even should "spontaneous generation" be discovered at some future time, the gap would yawn as wide as ever. We should still have to explain why matter contained such tremendous potentialities that, in appropriate conditions and under appropriate stimuli, it should be capable of giving rise to the phenomena of life. Even if that were explained, a yet wider gap lies ahead, beyond which alone we touch the still more tremendous fact of consciousness. If dead matter could be made to live or simulate the phenomena of life, there is no certainty that it would think and feel. Here we are once more on a different plane of being; the phenomena on each side of the gap are incommeasurable.

It is an appreciation of such logical chasms as these that retains the conception of vitalism in modern thought. After a period of discredit, due to a natural exaggeration of the newly discovered power of resolving the processes of living cells into the physics of colloids and the chemistry of the proteids, vitalism is again in the ascendant. As long as it is not made the excuse for ceasing to search for a physical or chemical explanation in any possible case, its resurrection may be welcomed as a recognition of the fact that first in life and then in consciousness we have new phenomena, on a different scientific plane to those of inorganic processes.

Thus vitalism does not depend on the difficulty 


\section{THE FOUNDATIONS OF SCIENCE}

of preparing the more complex organic substances which have hitherto defied the resources of our chemical laboratories. It does not depend on our failure to explain the more recondite physical and electrical phenomena of living cells, nor on our failure to manufacture life from inorganic matter. It is never safe to build conclusions on the mere gaps in knowledge. But it is required because we have to account for phenomena which are different in kind to those others-to account for growth, reproduction, for the unity of a complex organism, for the transcendent fact of consciousness, in short, for the problem of life itself. 


\section{CHAPTER IV}

PSYCHOLOGICAL SCIENCE

WE have now reached the last of our divisions of science-that which deals with the phenomena of mind, the organ by which we are enabled to apprehend the world as seen in the physical and biological sciences.

In the history of human thought, we find that, for a long while, the study of mind followed exclusively the methods of introspection; but in recent years experiment has been applied to mental phenomena also, and, for our purpose, it will be simpler to approach the subject from the experimental side.

We may begin by examining our sense-perceptions -properties of the human body, varying from individual to individual, giving rise to the sensations our minds experience when our senses are stimulated.

The sense of touch, by which we distinguish many physical properties, varies greatly when different parts of the body are affected, and for practical use often seems to be concentrated in the finger-tips. The sensitiveness of the nerves of the skin to a light touch may be estimated by exploring the skin with a series 


\section{THE FOUNDATIONS OF SCIENCE}

of fine hairs mounted on wooden handles. The pressure which each hair is capable of exerting is measured on a balance, and thus local differences in sensibility may be mapped out. Again, by exploring the skin with blunt-pointed rods, either hot or cold, the sensitiveness to heat and cold may be determined. It is found that some areas are more sensitive than others to each kind of stimulus, the "touch spots" not coinciding either with the " heat spots " or the "cold spots," and none of these being coincident with the "pain spots," where painful pressure is most easily felt.

If a nerve connected with a given sensory area of the skin be cut, the sensations are destroyed, and only return slowly as the injury is restored. The sensibility to pain returns first, and the feeling of cold before that of heat.

Thus we see that the extent to which the mind is influenced by effects of pressure or of temperature on the skin, does not depend alone on these outside variables. The properties of the portion of the body which is acting as receiving agent have to be taken into account.

The sensation of sight, like those of touch and hearing, is one which is possessed alike by mankind and the upper members of the animal world; though the range of the sensations probably does not correspond in the various instances. 
While intense radiant energy, such as powerful direct sunlight, affects the whole surface of our body, and gives to our minds the sensation of heat, the sensation of light is excited only when radiation of a certain type falls on our eyes. Their sensitiveness to radiation within a limited range is extraordinarily great, an infinitesimal amount of energy being enough to produce the characteristic sensation; but the kind of radiation which is effective is strictly limited, lying between definite limits of frequency of vibration of light waves from about 400 to 800 millions of millions per second, the greatest sensitiveness being about the middle of this range, in the yellow.

The sensations of light may be divided into colourless sensations-a white to grey and black linear series-and colour sensations which are more complex, and must be represented by some closed figure such as a circle or triangle. Beginning with the sensation of red, we may pass by insensible gradations either towards orange or purple. If the former, we reach successively, orange, yellow, green, blue, violet, purple, and so complete our circuit and return to red. If these colours be mixed with white or grey, we get less pure shades. If red be mixed with white or light grey, we get rose or pink; if with dark grey or black, the result is brown.

The sensation of white may be excited either by a mixture in the eye of all coloured lights, as in sunlight, which contains all the colours of the spectrum, 


\section{THE FOUNDATIONS OF SCIENCE}

or by mixing in the eye pairs of colours which lie opposite each other in our diagram-red and green, blue and yellow, greenish blue and orange. It must be noted that, in all these cases, rays of light must be mixed so as to be blended when they enter the eye. The mixture of pigments or paints outside the eye is another and more complicated story.

As we have said, it is probable that the extent and intensity of all sensations differ from person to person, possibly from race to race, on the average of large numbers of individuals. About four per cent. of European men are colour-blind to red and green, and see those colours as grey. Another much rarer type of human being seems to be blind to blue and yellow, while some others are totally colour-blind.

The common red-green blindness indicates that red and green are primary colour sensations, and so far all are agreed. But two explanations of the whole of the phenomena are held: according to Hering's theory, there are four primaries-red, green, blue, and yellow; while, on Young and Helmholtz's theory, all colour sensations are compounded of red, green, and blue, as figured in the triangle we used to illustrate another subject in Chapter I.

Primitive races seem to be much less sensitive to blue and rather less sensitive to yellow than Europeans, as though these sensations had not yet fully developed. It is interesting to note that in the Iliad of Homer colour terminology, except for red, 
and possibly yellow, is very vague, and we do not find definite words expressing the ideas of blue or brown.

The sensations of hearing, taste, and smell, have been less studied by experimental psychologists than those of touch and sight. The sense of pitch in sound is well known to vary largely in different individuals ; a rough estimate of its delicacy is sometimes formed by ability or inability to hear the squeak of the bat. It may be measured scientifically by testing sensibility with any source of sound in which the pitch is under control.

Here again, the differences noted between the powers of various individuals are probably at the base of many differences of opinion and judgment, believed to have a more intellectual " rationale."

Passing from direct sense-perceptions to the more recondite powers of the mind, we are met at once by the recognition of the importance of memory. Without memory we should be unable to co-ordinate our different states of consciousness; we should, in fact, lose our personality.

The tendency of past events, particularly if specially impressed on us at the time, to recur spontaneously, has been termed "perseveration." A thought that haunts us and prevents our sleep is a good illustration of this tendency.

The form of perseveration differs among individuals. Some recall a complete scene; others visualise form 


\section{THE FOUNDATIONS OF SCIENCE}

but not colour ; others revive most vividly sounds, tastes, or smells. To others the past scene is presented in words, either imagined as heard or as spoken in their minds. Finally, some remember in imageless thoughts.

The simpler phenomena of memory have been studied by measuring the number of repetitions needed before a series of meaningless syllables could be reproduced. The number requisite is found to increase rapidly with the length of the series. When, after a lapse of some time, they are partially forgotten, new experiments may be made, and it is now found that fewer repetitions are needed than at first. By the elaboration of such experiments, the effect of time, of new impressions, and of other complications, may be investigated.

Light may also thus be thrown on that most important property of our minds known as association. If the syllables be learnt in pairs, the first one of each pair being accented, they are easier to learn. Here a second sensation, that of rhythm, is probably introduced. Moreover, if one of the accented syllables be exhibited afterwards, it is easier to recall the one that follows than if the non-accented syllable be exhibited. More complex associations are also found between groups of several syllables; while the greater rapidity and completeness with which syllables are learnt when they make sense, shows the effect of association between sounds and meaning. The ad- 
dition of rhythm, accent, and rhyme with sense, complete the association which accounts for the greater ease most people experience in committing verse to memory rather than prose.

The most marked lapse of memory occurs immediately after the impression has first been made. Associations ten minutes old are less perfect than those tested at once after learning, while the differences between ten minutes and twenty-four hours are not so marked. Mere perseveration is especially prone to lapse with time, much more so than the complicated associations involved in rational learning when the meaning of a lesson is fully grasped.

It is by association that much of our pnysical and mental power is built up. An infant has no power of co-ordinating the movements of its limbs, and only gradually does the habit of associating appropriate movements result in ability to walk and speak. Increase, with practice, of skill in handicrafts, is another illustration of the same effect.

Part of education consists in the formation of associations. From the simple effort of memory involved in the association of five times seven with thirty-five, to the facility of a more advanced mathematician in the solution of differential equations by the power of association, we save ourselves the mental labour of working out problems each time afresh from first principles.

The whole of that part of military training known 


\section{THE FOUNDATIONS OF SCIENCE}

as discipline is an affair of association, whereby, when orders are given, the obedience becomes mechanical and independent of the will, and the army becomes a tempered weapon in the hands of its commander. Most of politics may be taken as an illustration of the power of association. The art of electioneering in especial consists in impressing on the minds of the electors the association of their ideas of the blue party and Smith, the blue candidate, with the idea of peace, cheap food, and reform, or a strong Empire and work for all, and connecting the idea of Jones, the buff candidate, with Chinese slavery, a dear loaf, a refusal to "tax the foreigner," or other unpopular and possibly irrelevant conceptions. The preliminary stage may involve a good deal of more or less rational discussion; but, as the polling day approaches, excitement rises, and preformed associations take most of those who vote to the poll at the last.

In the methods of modern electioneering, elaborated according to long experience in political psychology, it is probable that there is an actual disadvantage in having a candidate who is resident in the constituency, since he inevitably becomes associated in the minds of the voters with commonplace occurrences of daily life and useful enterprise, and consequently the simplicity of association between the idea of the candidate and the ideas of the electioneering virtues tends to be obscured. 
The old intellectualist theory, the theory on which indeed modern democracy was founded, taking no account of the irrationality of mind under certain stimuli, is more and more discredited by observation, though possibly other equally valid new foundations may be discovered in the future for the system to which it gave birth.

In the introspective part of psychology, though far older in point of time, less general agreement has been reached than in the experimental branch of the subject. Since the time of Kant (1724-1804), it has been usual to divide our direct mental relation with objects into three types of conscious activity. We know or apprehend an object, we feel pleased or pained by our perception, and consequently we form some wish or desire about it. These three states are sometimes termed cognition (or knowing), feeling, and conation (or willing). Since feeling and willing seem more nearly allied than either of them is to knowing, there is now a tendency to revert to a dual classification, feeling and willing being grouped as sub-divisions of interest.

The special characteristic of the human mind is its power of constructing complex ideas and of following trains of thought. In this process association plays a part: association not only of impressions which have chanced to coincide or follow each other regularly in the past, but also association of similars 


\section{THE FOUNDATIONS OF SCIENCE}

which may not have been associated before in time or space. Here a new formative process appearsthe process of comparison. We see a tiger, and it suggests to our mind the remembrance of a cat. We thus consciously compare the cat and the tiger, and form a concept of a feline or cat-class of animals of which the tiger and the cat are varieties, and all tigers and cats we know are members. Such a concept also involves the possibility of the existence of other animals of the class, unknown to us, and assists us in any search for them and in the identification of them.

And here we see the psychological importance of language : the possibility of giving all similar animals the general name of cat, assists the mind to frame the idea of a universal or general concept of cat. In this it merely helps to clarify the results of senseperceptions; but it may also be used to inform us that cats have many interesting properties, such as the possession of nine lives, which we have not ourselves had the benefit of testing, and may incorporate these qualities in our future concept of cat. Thus may be elaborated a process of conceptual synthesis.

The mental processes of which we are conscious do not represent the whole of the workings of our minds. Sub-conscious changes, apparently independent of voluntary control, may go on, and their results emerge into consciousness at a future time. A problem 
studied unavailingly at night, and solved immediately on regaining consciousness after sleep, serves as one example of this process. More striking cases are shown in the phenomena of hypnotism, where suggestions made by some outside person to the subject during trance may affect his actions, not only while in the hypnotic condition, but after recovering therefrom and being apparently in a normal state of self-control. Extreme instances are found in the rare cases of dual or multiple personality, where an injury to the brain or an unnatural sleep, or the action of drugs, has resulted in complete loss of memory of past life, and sometimes in the modification of the old mental qualities. A return to the first personality is not unknown, when forgetfulness of the life of the second personality may ensue. Several alternations between the two personalities have been noted and described.

Evidence has been obtained that ideas may be transmitted directly from mind to mind without the use of normal sense-perception, while other phenomena affecting mind in abnormal conditions have been interpreted by some observers as indicating the action on living minds of consciousness associated with the personalities of the dead.

A close correspondence has been traced between psychological states and changes in the nervous system. Sensations are set up by the transfer of a nervous impulse along one set of nerves from the 
surface of the body to the brain, and movements are carried out in response to other impulses which travel from the brain along another set of nerves.

Different parts of the brain have been shown by physiologists to play different functions. But the co-ordination and harmonious use of different functions needs a special nervous mechanism; thus the third convolution of one or other hemisphere of the brain is concerned with the correlation of the movements of the throat and larynx, which occur in speech, and any injury to that convolution results in aphasia, or loss of the power of speech. It seems likely that the co-ordination and grouping of ideas required in the high mental processes, is different in kind to the simple constituents, and is more than the mere aggregation of those constituents.

Evidence shows that to every psychological state there exists a corresponding physiological process in the brain, and to every physiological process appropriate physical and chemical changes in nerve substance.

This psycho-neural and psycho-physical parallelism is a matter of observation and experiment, and is one of the joint conclusions of psychology and physiology. It is unnecessary for the purposes of science, psychological or physiological, to frame any hypothesis as to whether or no the subjective processes of consciousness are directly connected with the objective phenomena of nerve-change which accom- 
pany them. Such inquiries are of fundamental importance to mankind, but they are problems of that branch of philosophy known as metaphysics, and are not problems which psychology or any other science can answer or need ask. Just as the function of physical science is to construct a mental model of nature seen in a physical light, and the function of biology is to represent it in a biological light, so psychology constructs a mental model of that part of nature which involves mind from its own special point of view. Its function is to construct a consistent model, not to seek the answer to the more fundamental question whether that model corresponds completely with reality. That inquiry is reserved for metaphysics. Moreover, psychology cannot even rightly investigate the connection between its own model and that of physics or biology. They are, so to speak, on different planes, and cannot of themselves get into contact. The true connection, or want of connection, between them is a part of the study of reality-that is a problem of metaphysics.

Metaphysicians have formed four hypotheses on this particular point. There is the metaphysical theory of psycho-physical parallelism, which exalts to the state of an ultimate truth that parallelism of two independent series which psychologists take merely as a convenient scientific working hypothesis. According to this dualistic theory, our conscious thoughts and our neural changes are for ever keeping 
step, though between them is fixed an impassable gulf, across which there is no possibility of interaction.

The second theory is that of the materialist, who holds that the physical changes are the sole reality, and that consciousness is merely a bye-product of atomic and molecular rearrangements.

The third theory is called idealism, and, according to it, mind is the only ultimate reality, and matter is one of the manifestations of some finite or infinite mind.

Finally, there is another dualistic theory which regards mind and matter as distinct, but accepts the common-sense view that our minds act on and are acted on by matter, leaving undetermined as yet the precise mode of interaction.

It is beyond our present purpose to discuss these metaphysical theories.

We are now in a position to consider in more detail the theory of knowledge, to ask, in fact, how knowledge becomes possible, whether in one way or in more than one. Here we are on debatable, or, at all events, debated, ground, and not all philosophers will agree with the statements in the next paragraphs.

One kind of knowledge which we dealt with in the chapters on physics and biology may be termed knowledge by experience. It may be sub-divided into knowledge by acquaintance and knowledge by description. Knowledge by acquaintance may be 
acquired by direct sense-perception, when what we know is the perception-the sensation of green when we look at grass, or the sensation of force when we stop a moving ball. But it may also be derived from memory, which makes us aware of what we remember by the direct action of the mind. Thirdly, another sort of knowledge by acquaintance is acquired by introspection, in what is called self-consciousness. When we see the grass, we may be aware of our seeing the grass, aware of our own mental state and mental action. Self-consciousness is the source of all our knowledge of our own mental life.

The other division of knowledge by experience is that kind which is acquired by description. Our knowledge of the grass, as distinct from our knowledge of our sense-perceptions of it, is knowledge by description. It involves the memory of a number of descriptions of the qualities of the grass, either discovered by ourselves or supplied to us by others by the help of language. Our concept of grass involves such properties as being green, of being good food for cattle, of being made of growing vegetable cells, themselves composed of molecules, atoms, or electrons. We cannot be aware by acquaintance or direct mental action of the grass, only of our senseperceptions; we only know the grass, if we can be said to know it at all, by consciously or unconsciously putting together a number of descriptions of it. 


\section{THE FOUNDATIONS OF SCIENCE}

We now pass to the consideration of a different class of knowledge, where we come in contact with the principles of logic and of pure mathematics or symbolic logic. One school of philosophers-the "empiricists"- hold that here too all our knowledge is acquired by experience. An opposing school, the rationalists, hold that logical principles are grasped by an intuitive action of the mind, and are not proved by experience, though they may be and usually are suggested by experience.

Thus the truth that two and two are four or the axiom that things that are equal to the same thing are equal to each other, may be suggested to a beginner in mathematics by the process of counting four real objects or by the actual measurement of the equal lengths. As soon, however, as he has grasped the meaning of these propositions, he recognises general truths which are true not only of the objects or lines used to illustrate them, but must be true of all things at all times and in all conditions.

This result is different in kind to the propositions which need the support of all possible instances for their belief, such propositions as we meet with in the subject-matter of natural science. The statement that all chemical elements were unchangeable was gradually established by a long series of failures to transmute them one into the other, till it became a principle universally accepted : the probability in its favour was enormous. Yet the discovery of the 
spontaneous disintegration of radioactive elements irto simpler atoms shows that, in such matters, certainty cannot be reached. We can conceive of a world where all chemical elements are unstable, where energy is not constant, or where masses do not gravitate; but we cannot conceive of a world in which two and two do not make four, or where things equal to the same thing are not equal to each other.

Such logical principles, then, are known to us by intuitive apprehension. They have often been treated as laws of thought, and in this view are a subject of psychology as well as the root of logic and pure mathematics.

But, besides being laws of thought, in accordance with which we are compelled to think, they are true in the external world. Two shillings and two shillings in actual experience always make four shillings, in accordance with the general principle that two and two make four. Hence, some philosophers hold that the laws of thought give us certain knowledge about a real world, the world of universals, and are laws of nature rather than laws of thought. But others would hold that the fact that our laws of thought are in accordance with the particular instances that happen in nature is a matter of experience, and might conceivably fail us. On this view it seems better to take such self-evident logical principles as a foundation for our purely ideal and universal constructions 


\section{THE FOUNDATIONS OF SCIENCE}

of logic and pure mathematics, and leave to experience and experiment the task of examining how far they are true in substance and in fact in the concrete cases of the external world of phenomena. Nevertheless, the evidence for the external particular truth of such principles is greater in degree, perhaps different in kind, to the evidence for the truth of any one physical law, such as the proportionality between electromotive force and electric current, or any physical theory such as Newton's theory of gravity. The evidence for such laws and theories is special in kind, though it may be of very great extent. But the evidence that logical principles are of true application in nature is not special but general. All our experience of whatever kind is consistent with it, and hopeless intellectual confusion would follow any breach in its observance: no science, no ordered knowledge would be possible.

Formal logic has made great progress since it began to use symbols, already familiar in mathematics. Symbols not only serve as a shorthand method of writing down relations which it would be tedious and cumbersome to express in words, but also they represent an analysis of ideas and an almost pictorial representation of them.

Thus it is one of the fundamental laws of algebra that a first number $(x)$ multiplied by a second number $(y)$ gives a product which is equal to the product obtained by multiplying the second number by the 
first. This law is expressed not only more concisely but also more clearly by the symbolic equation-

$$
x y=y x \text {. }
$$

In this way we can perform operations of reasoning almost mechanically, which otherwise would require careful and tiring thought.

"Civilisation advances by extending the number of important operations which we can perform without thinking about them. Operations of thought are like cavalry charges in a battle-they are strictly limited in number, they require fresh horses, and must only be made at decisive moments." 1

Now, all this intuitive knowledge, whether expressed in words or symbols, is not knowledge about things. It is knowledge about the relations between universals. In our equation, $x$ and $y$ stand for any two quantities whatever-any number of apples or shillings or feet or hours. The ideas of multiplication also, and of equality, are general ideas, not confined to a particular operation or a particular identity.

Thus the knowledge we gain intuitively is not knowledge about natural objects or natural phenomena. It is concerned with a purely ideal world, a world of universals.

If we wish to apply this knowledge to natural processes, we must turn to experience; and here we touch the experimental sciences with which we

1 Dr. A. N. Whitehead, Introduction to Mathematics. 


\section{THE FOUNDATIONS OF SCIENCE}

began our survey. Our experience gives us data on which to reason; particular instances to which we may apply our intuitive knowledge of the relations between universals.

Our experience gives perceptions which suggest the corresponding concepts of length, time, and force, and from them we divine the secondary concept of mass, related to force by the definition that a mass $(m)$ is measured by the force $(f)$ required to give it unit acceleration. Hence we get the symbolic statement-

$$
f=m \times a .
$$

This relation is suggested by our experience of the force required to set masses in motion, but, in its accurate form, it is a consequence of our definition of mass. Thus, strictly, we can only know that it applies to the conceptual world. Given our concepts of length, time, and force, and our definition of mass, the relation $f=m a$ is a consequence of our logical laws of thought, and gives only a necessary relation between our ideal concepts of universals.

But, as a matter of experience, we find that this relation serves as a valid basis for the practical science of dynamics. To build that science, we need further experience of actual cases. Newton, associating the fall of an apple with the fall of the moon, makes the hypothesis of an attracting force between masses to explain both. Deducing by logical intuitive principles the consequence of the 
hypothesis, he finds that they agree with observed facts. The hypothesis is verified in one case.

Next it is shown sufficient to explain also the motion of the planets round the sun in ellipses. It is verified in a second case. It proves able to account for all the complicated perturbations of the moon's orbit, and even to disclose the existence of a hitherto unknown planet from its disturbing effects on others.

Each new step in this process of induction gives the mind a new feeling of security in further applications of the theory. It becomes more and more probable that the next test will again prove its power; more and more probable, indeed, that the theory is of universal validity, that it represents a general law of nature. Thus by induction we pass from particular to particular and from particular to general.

Nevertheless, we never reach logical certainty; we can only approach certainty more nearly, as instances of the successful application of the theory multiply under our hands. There is no such thing as certainty in natural science; it is an affair of probabilities. A radium atom may behave as a permanent institution for a thousand years, and in one surprising moment explode into fragments at the last.

Yet, in science no less than in practical life, we are dependent on induction at every step. In practice it is necessary to assume that because the 
sun has risen every yesterday it will rise to-morrow, and in science it is necessary to assume that an electric current, as in the past, will always exert a magnetic force. The inductive principle of prediction cannot be proved by experience, for, as regards future cases, it is the inductive principle alone which can justify any inference from past cases. The principle of induction, then, is itself involved in any attempted proof of it which appeals to experience. Hence, like the laws of thought, it must be accepted on its intrinsic evidence as a piece of intuitive knowledge. We feel instinctively that any event which has occurred before may recur again, and that, the oftener it has occurred before with no exception, the greater the probability of its recurrence : and there we must leave it.

We have now completed our circuit of the sciences, and have returned to our starting-point, where logic and mathematics are applied to the study of nature, and especially, and in the first place, to that aspect of nature given by mechanics.

And here our brief survey of an inexhaustible field must close. It is contrary to our aim to examine into the details of any one science. It is also beyond our mark to deal with the metaphysical problems of the nature of reality, which need all knowledge for their study and are represented in our original diagram by the spot of blinding white light at the centre. 


\section{PSYCHOLOGICAL SCIENCE}

Unlike natural science, metaphysics has yielded no general agreement in results. Perhaps no definite and certain results are possible, and the metaphysician may be obliged to remain for ever upheld by the conviction that it is better to learn how to frame aright questions of high dignity and import, than to solve successfully the lowlier problems of natural science.

\section{BIBLIOGRAPHY ${ }^{1}$}

The Grammar of Science (Karl Pearson: A. \& C. Black, 7s. 6d.), and Science and Hypothesis (Henri Poincaré; Translation: Scott, 3s. 6d.), are two treatises on the philosophy of science. The Preface to An Introduction to the Theory of Optics (A. Schuster : Arnold, 15s. net) is valuable as a general comment upon the limits of scientific progress. These may be read for their treatment of science in general.

The Recent Development of Physical Science (W. C. D. Whetham: Murray, 5s.), gives a description of modern work in physics suitable for the general reader. The Science of Life (J. A. Thomson: Blackie, 2s. 6d.), an historical account of the development of biology.

An introduction to the various branches of science mentioned in this work will be found among "The People's Books," each volume of which has been specially written to be of use to general readers, and contains a guide to further reading.

1 This list of books has been drawn up by the editor of "The People's Books." 


\section{N D E X}

ETHer, the, conception of, 49, 50

Anatomy, early researches in, 52 Astronomy, gravitational, 26-28 Atomic theory, 34, 35

BActeriology, 61

Bequerel rays, 46

Biological science, 7, 8, 51-70 author's colour theory of, 9-12

Botany, early researches in, 53, 54

Burning, phenomena of, 35

Chemistry, 35,67 of celestial bodies, 42

Colour sensations, 73

DrNasics, early researches in, $16,17,19$

Eufctrical science, development of, 43

theory of matter, 49

Eugenics. 58

Evolution of species, 55

Faraday's researches in electricity, 43

Gatrueo, on law of velooity of fall, 19-27

Geology, early researches in, 55

Heat, nature of, 36 et seq.

Helium, 42

KNOWLEDGE, theory of, 85

Lever, law of the, 16, 18

Light, nature of, 39 et seq. sensations of, 73

Logic, inductive, 86,91
MALARIA, 63

Malta fever, 65

Matter, electrical theory of, 49 nature of, 34

Mechanical science, 16, 29

Medical science, $52,53,65,66$

Memory, 75, 76

Mendelism, 59

Microbic diseases, 61

Microbiology, 61

Molecular theory, 34, 35

Natural Selection, 56

Newton, Sir Isaac, 26, 28, 32 , $33,34,36,39$

Perseveration, 75

Physical science, 7-11, 16-50

Physiology, 11, 12, 53

Psychological science, 9, 10, 12, 71-93

RADIO-ACTIVITY, 47

Radium, 47

Röntgen rays, 45, 46, 47

Sorences, the, author's colour scheme of, 9-15 divisions of, 7

Sense perceptions, 71

Statics, 17, 18, 19

Thermod ynamics, 38,39

Velocity, law of, 19-26, 29 of light, 33

Vitalism, 68, 69

Voltaic pile, the, 43

WAVE theory of light, 40

YeAST, fermentation of, 62, 63

ZooLogy, early researches in, 54 




\section{PLEASE DO NOT REMOVE \\ CARDS OR SLIPS FROM THIS POCKET}

\section{UNIVERSITY OF TORONTO LIBRARY}

r\&A Sci 
